\title{
Экономическая добавленная стоимость. Концепции. Подходы. Инструменты
}

\author{
Ивашковская И.В. ${ }^{30}$, Кукина Е.Б. ${ }^{31}$, Пенкина И.В. ${ }^{32}$
}

JEL: G30, G34

Ключевые слова: экономическая прибыль, стратегическая эффективность компании, драйверы стоимости компании, стоимость компании, управление стоимостью компании.

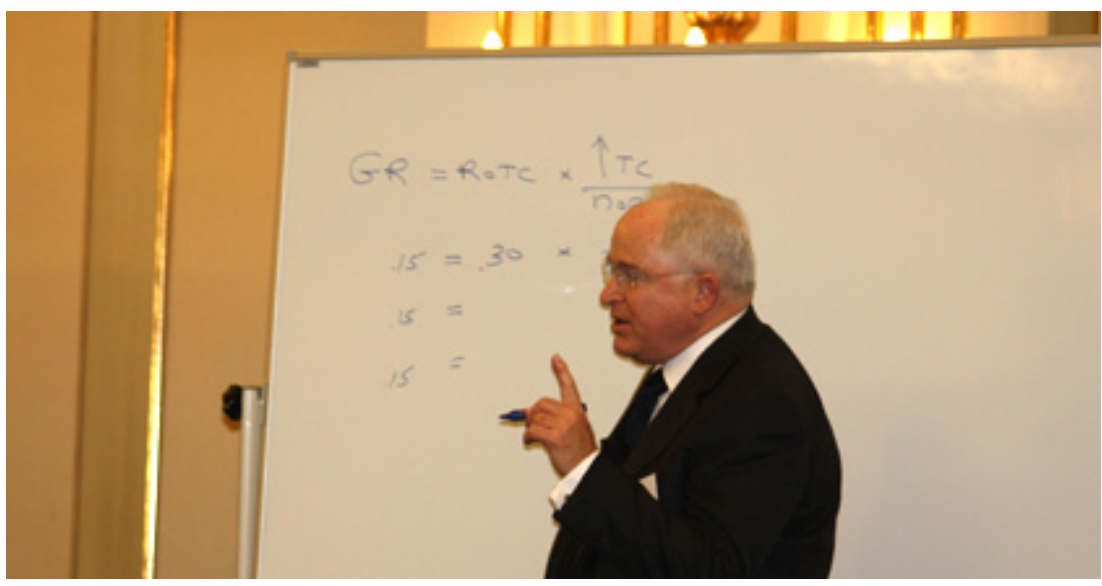

КПМГ ${ }^{33}$ - международная сеть фирм, предоставляющая аудиторские, налоговые и консультационные услуги, в июне 2010 года провела открытую конференцию, посвященную экономической добавленной стоимости, ее принципам и методикам. Конференция стала знаковым событием в мире российского бизнеса, которое обозначило признание необходимости применения новых и современных концепций для управления. Специально для этой цели на конференцию были приглашены руководители крупнейшей международной консалтинговой компании Stern Stewart \& Co, а появление Джоэла Стерна одного из основателей компании - стало беспрецедентным событием для подобного рода мероприятий в России.

Компания Stern Stewart \& Co (www.sternstewart.com) является одним из лидеров в области стратегического консультирования и управления на основе стоимости. Созданная в 1982 году в Нью-Йорке, она стала пионером в области экономики бизнеса и прикладных корпоративных финансов. В конце 1980-х годов была разработана и запатентована новая концепция управления на основе экономической добавленной стоимости EVA ${ }^{\circledR}$, которая на сегодняшний день является наиболее проработанной и популярной среди многих компаний. Stern Stewart \& Со имеет свои офисы в Северной Америке, Европе, Латинской Америке Австралии, Китае, Индии, ЮАР, других странах Азии и Африки. Россия оказалась практически единственной страной, в которой в большинстве своем отсутствуют анализ на основе стоимости и услуги консалтинга в области управления стоимостью. На конференции

\footnotetext{
${ }^{30}$ Профессор, заведующая кафедрой экономики и финансов фирмы, заведующая научно-учебной лабораторией корпоративных финансов Государственного университета - Высшей школы экономики.

31 Стажер-исследователь научно-учебной лаборатории корпоративных финансов факультета экономики Государственного университета - Высшей школы экономики.

${ }_{32}^{32}$ Старший менеджер отдела управленческого консультирования КПМГ в России и СНГ.

${ }^{33}$ КПМГ - это международная сеть фирм, предоставляющих аудиторские, налоговые и консультационные услуги. В офисах КПМГ в 146 странах мира работают 140 тыс. сотрудников. Независимые фирмы - члены сети КПМГ входят в ассоциацию KPMG International Cooperative (“KPMG International”), зарегистрированную по законодательству Швейцарии. Каждая фирма является независимым юридическим лицом.
} 
с основным докладом выступил Джоэл Стерн, создатель и разработчик концепции и понятия «экономическая добавленная стоимость» $\left(\mathrm{EVA}^{\circledR}\right)$ как показателя эффективности деятельности компании и системы управления на основе $\mathrm{EVA}^{\circledR}$.

По просьбе компании КПМГ Научно-учебной лабораторией корпоративных финансов ГУ - Высшей школы экономики (www.cfcenter.ru) в марте - мае 2010 года было проведено совместное с отделом управленческого консультирования КПМГ исследование, посвященное практикам управления в российских компаниях и анализу факторов их стоимости. Результаты этого исследования были оглашены на прошедшей конференции. В рамках конференции были представлены доклады участников:

- Джоэл и Эрик Стерны (Stern Stewart \& Co): Концепция стоимости и ее актуальность. Экономическая добавленная стоимость как концепция управления.

- Ховард Полиньски (партнер отдела управленческого консультирования компании КПМГ в России и СНГ) и Ирина Ивашковская (заведующая кафедрой экономики и финансов фирмы и научно-учебной лабораторией корпоративных финансов ГУ ВШЭ): Результаты исследования КПМГ и ГУ ВШЭ: анализ экономической добавленной стоимости в российских компаниях и применение российским бизнесом практик управления стоимостью.

Программа конференции была построена таким образом, чтобы дать возможность делегатам ознакомиться с основными принципами и понятиями управления стоимостью и принять участие в дискуссии об оптимальных способах их применения на российском рынке.

Ключевые вопросы докладов представлены далее.

\section{Преимущества экономической добавленной стоимости: точка зрения разработчика концепции}

Джоэл Стерн известен прежде всего своей концепцией экономической добавленной стоимости $\left(\mathrm{EVA}^{\circledR}\right)$, которую он разработал совместно со своим партнером Беннеттом Стюартом. $\mathrm{EVA}^{\circledR}$ - это простой метод, который стал популярной темой как в компаниях по всему миру, так и в академической среде. Ее смысл сводится к тому, что фирма должна генерировать потоки свободных денежных средств, которые приносят прибыль, превышающую необходимую норму доходности.

C точки зрения управления определение эффективности компании является ключевым вопросом: от ответа на него зависят материальные выгоды собственников, бонусы управляющего звена, определение стратегии компании и многие другие вопросы.

Использование простых бухгалтерских показателей для оценки эффективности компании и управления компанией не позволяет сделать это адекватно, поскольку природа расчета зачастую не отражает их справедливую оценку. Альтернативные подходы, которые изначально применялись в том числе и в Stern Stewart \& Co, были основаны на моделях дисконтирования денежных потоков (DCF) или внутренней нормы доходности (IRR). Но при таких подходах значительная часть стоимости компании связана с постпрогнозным периодом. На практике его определение сопряжено со значительными трудностями в прогнозировании. Кроме того, эти оценки статичны, измеряя только будущее, EVA ${ }^{\circledR}$ помимо этого дает наглядное представление, что принесла компания своим инвесторам за истекший временной срок. Противоречивыми оказываются и оценки эффективности бизнеса, которые можно получить при использовании оценочных мультипликаторов. Определяя в качестве оценки эффективности компании темпы роста прибыли (NOPAT), необходимо учитывать причину ее изменения. Высокие темпы роста прибыли могут являться следствием как высокой доходности используемого капитала (ROTC), так и значительными новыми инвестициями (INV) при низкой доходности: 


$$
\frac{N O P A T_{t+1}-N O P A T_{t}}{N O P A T_{t}}=R O T C \times \frac{I N V}{N O P A T_{t}},
$$

где:

$$
R O T C=\frac{N O P A T}{T O T A L_{-} C A P I T A L},
$$

NOPAT (Net operating profit after tax) - посленалоговая операционная прибыль.

Экономическая добавленная стоимость $\left(\mathrm{EVA}^{\circledR}\right)$ - это показатель экономической прибыли. Она рассчитывается как разница между чистой операционной прибылью после вычета налогов (NOPAT) и платы за весь инвестированный в компанию капитал с учетом специальных поправок к прибыли и капиталу, называемых эквивалентами собственного капитала в концепции $\mathrm{EVA}^{\circledR}$.

$$
\text { (3) } \quad E V A^{\circledR}=N O P A T_{e e}-W A C C \times C E_{e e}
$$

В относительных показателях формула преобразуется к следующему виду:

$$
\text { (4) } E V A^{\circledR}=(R O T C-W A C C) x C E_{e e} \text {, }
$$

$N O P A T_{e e}$ - посленалоговая операционная прибыль, скорректированная;

WACC (Weighted Average Cost of Capital) - средневзвешенные затраты на капитал;

$C E_{e e}$ (Capital Employed) - сумма инвестированного капитала, скорректированая;

ROTC (return on total capital) - доходность инвестированного капитала.

Одно из ключевых отличий $\mathrm{EVA}^{\circledR}$ от других показателей эффективности, таких как чистая прибыль на акцию (EPS), прибыль до уплаты налогов, процентов, износа и амортизации (EBITDA) и прибыль на инвестированный капитал (ROTC), заключается в том, что она учитывает все расходы на ведение бизнеса: фактические (явные) и альтернативные (неявные) издержки. Таким образом, она позволяет инвесторам сравнить доходность, приносимую капиталом компании, с альтернативными издержками вложения своих средств. Учет всех издержек дает возможность корректно оценивать фундаментальную стоимость компании, рост которой и является итоговой целью любой корпоративной стратегии.

Кроме того, для расчета $\mathrm{EVA}^{\circledR}$ исходные бухгалтерские данные берутся скорректированными. Эти корректировки имеют целью отразить действительные объемы ресурсов и стратегическую направленность их использования с учетом отраслевых особенностей и тем самым устранить недостатки стандартов бухгалтерского учета.

Независимо от того, идет ли речь о компании в целом, либо о ее бизнес-подразделении, - $\mathrm{EVA}^{\circledR}$ позволяет контролировать создание стоимости на соответствующем уровне исходя из соотношений составных компонентов при росте или рентабельности инвестированного капитала (ROTC), или инвестиций, когда подразделение или компания в целом способно принести инвестору больше чем его требуемая доходность. Или же отказ от тех направлений деятельности, которые не способны обеспечить положительную разницу между ROTC и WACC. Несмотря на то что эти условия достаточно прозрачны, на практике оказывается, что компании «разрушают свою стоимость», демонстрируя отрицательные значения $\mathrm{EVA}^{\circledR}$ : на американском рынке такое происходит с $60 \%$ всех фирм, при анализе российского бизнеса эта цифра составила $40 \%$.

Говоря о корректировках, которые осуществляются при определении $\mathrm{EVA}^{\circledR}$, они будут использоваться для разных типов бизнеса: добывающего, сервисного, финансового, промышленного, поскольку каждый раз драйвером стоимости будут являться различные типы активов, которые не учитываются в стандартных методиках бухгалтерского учета.

Так, для компаний нефтегазовой отрасли необходимо проводить корректировки, учитывающие следующие моменты. Реальными драйверами роста компаний этой отрасли (65-80\%) являются имеющиеся запасы нефти и газа, уровень их добычи, доступность и 
другие связанные натуральные показатели. Для корректной оценки меры стратегической эффективности следует также проводить капитализацию расходов на НИОКР. Расчет EVA ${ }^{\circledR}$ upstream (добывающий сегмент), EVA $^{\circledR}$ downstream (перерабатывающий сегмент) должен основываться на различных основаниях и требует различных корректировок. В первом случае они относятся в первую очередь к капитализации расходов от разработок тех месторождений, которые являются пустыми. Во втором случае корректировки будут в целом такими же, как для производственных компаний. Помимо этого, необходимо также принимать в расчет степень диверсификации компании.

Одной из составляющих системы управления стоимостью является вознаграждение тех лиц, которые влияют своими решениями на стратегическую эффективность бизнеса.

На основе показателя $\mathrm{EVA}^{\circledR}$ строятся механизмы вознаграждения руководителей на уровне всей компании и ответственных лиц за отдельные подразделения. В основе определения механизма вознаграждения лежит прямая зависимость между получаемыми выгодами и степенью риска. Эта зависимость не имеет верхнего или нижнего пределов, которые используются в традиционной системе вознаграждения, основанной как правило, на бухгалтерских показателях. Использование единого показателя для оценки эффективности компании и для вознаграждения приводит к тому, что у менеджеров появляются стимулы создавать стоимость для инвесторов, поскольку большая стоимость будет означать для них и большие бонусы. Для сохранения долгосрочной мотивации менеджеров используется зависимость не от абсолютных значений показателя (которая при прочих равных будет стимулировать их искусственно завышать показатель), но в большей степени от изменения его во времени. Это же устраняет проблему выплаты при отрицательном значении EVA ${ }^{\circledR}$. Более того, на практике формируется так называемый «банк бонусов», который предусматривает накопление подлежащих к уплате бонусов в будущем. Выплаты основаны на принципе равенства получаемых выгод при одинаковых результатах.

Такая система позволяет, с одной стороны, сделать менеджеров более заинтересованными в будущем фирмы, а с другой - сгладить отрицательное влияние неблагоприятных внешних факторов, которые также оказывают влияние на деятельность компании и ведут к падению $\mathrm{EVA}^{\circledR}$.

\section{Практики управления в российском бизнесе и предпосылки внедрения концепции управления стоимостью}

В марте-мае 2010 голода компанией КПМГ и Лабораторией корпоративных финансов ГУ ВШЭ было проведено совместное исследование, в рамках которого проводился опрос руководителей российских компаний о существующих практиках управления.

Полученные результаты исследования свидетельствуют о том, что практики управления на основе стоимостного мышления остаются для российского бизнеса недостаточно широко распространенными. В четверти опрошенных компаний управление осуществляется на основе стоимости, а в $60 \%$ имеются лишь элементы использования стоимостного подхода (преимущественно в отношении решений относительно инвестиционных проектов). В 17\% компаний этот подход не применяется.

Одна из главных проблем, которую видят руководители в создании системы управления на основе стоимости, - это трудности в перераспределении целей на уровне компании по ее отдельным функциональным бизнес-единицам, а также трудности в определении принципов управления для конкретной отрасли. В результате сегодня основными критериями эффективности деятельности компании выступают различные бухгалтерские показатели, такие как чистая прибыль и темпы роста выручки. Недостаток единого стоимостного мышления приводит к использованию разных критериев эффективности по отдельным элементам системы управления: так, например, стратегические цели устанавливаются преимущественно в таких терминах, как доля рынка, рост выручки или чистая прибыль, а для мотивации сотрудников - в чистой прибыли или в 
привлечении новых клиентов. Таким образом, отсутствие единого показателя как ориентира для создания фундаментальной стоимости может приводить к конфликту интересов внутри подразделений компании, что ведет к риску снижения стратегической эффективности фирмы.

Но несмотря на эти проблемы, в российских компаниях есть объективные предпосылки, которые будут способствовать реализации внедрения системы управления стоимостью. Среди них выделяются следующие: применение стоимостных критериев для оценки инвестиционных программ (на основе показателей чистой приведенной стоимости $\mathrm{NPV}$, внутренней нормы доходности - IRR), преимущественно дивизиональная организационная структура, которая позволяет выделить «центры стоимости» и достаточно полные системы сбора необходимых данных.

На практике внедрение стоимостного мышления (полного или частичного) для российских компаний сегодня в первую очередь находит отражение в повышении качества управленческих решений (это отмечают $63 \%$ респондентов) и в увеличении чистой прибыли бизнеса (25\%). Однако рост рыночной капитализации или рост доходности инвестированного капитала и качества инвестиционных решений отмечается лишь в 13\% случаев.

\section{Драйверы экономической прибыли российских компаний}

Определение ключевых факторов экономической прибыли как меры стратегической эффективности деятельности компании является необходимым для создания эффективной системы управления стоимостью. Вторая часть совместного исследования КПМГ и Лаборатории корпоративных финансов ГУ ВШЭ была посвящена определению этих факторов для российских компаний на основе эконометрического анализа. Работы, посвященные проблематике экономической прибыли, Лаборатория проводит с 2006 года. За это время осуществлены исследования по следующим направлениям: исследование объясняющей способности экономической прибыли относительно рыночной капитализации, основанное на данных телекоммуникационных компаний стран с развивающимися рынками капитала [Ивашковская, 2010]; влияния корпоративного управления на стратегическую эффективность компании, измеренную экономической прибылью на данных крупных российских компаний [Ивашковская. 2009]; анализ устойчивости и качества роста крупных российских компаний на основе экономической прибыли [Ивашковская, Животова, 2009].

Методология настоящего исследования основана на упрощенной формуле экономической прибыли, которая в своем расчете учитывает интересы только собственников акционерного капитала компании. Экономическая прибыль определяется через спрэд доходности: разницу между фактической доходностью на собственной капитал (как отношение чистой прибыли к инвестированному собственному капиталу) и требуемой собственниками $(\mathrm{Ke})$, как показано в формуле (5). Для целей проделанной работы бухгалтерские данные брались без специальных корректировок:

$$
\text { Spread }=\frac{N I}{E}-K e \text {. }
$$

Для определения детерминант экономической прибыли за период 2005-2008 годов были рассмотрены 68 крупных российских компаний - представители практически всех крупнейших отраслей в экономике России. В основе анализа положено построение двух моделей, одна из которых сосредоточена на финансовых и отраслевых переменных, вторая на переменных, качественно характеризующих финансовую архитектуру компаний.

Результаты проведенного регрессионного анализа на панельных данных, учитывающих временную структуру выборки, позволяют сделать следующие выводы о детерминантах экономической прибыли как драйверов стоимости бизнеса. 
Полученная зависимость спреда экономической прибыли от преимущественно финансовых факторов показывает значимое положительное влияние операционной рентабельности, темпов роста выручки, делового риска компании (отражающим волатильность операционных показателей компании во времени), присутствием иностранных инвесторов среди акционеров. К незначимым относится влияние отраслевых факторов, структуры и размера капитала.

Вторая модель, направленная преимущественно на выявление роли факторов финансовой архитектуры компании в создании стоимости позволила обнаружить положительную связь между показателем спреда и доли акций компании в руках первых трех крупнейших акционеров, доли независимых директоров, размера капитала компании. Среди отрицательных факторов было определено значимое влияние наличия институциональных инвесторов среди собственников компании и размера совета директоров. Структура капитала также оказалась незначимой.

В целом обе модели имеют хорошей объясняющей способностью: полученные значения $\mathrm{R}^{2}$ составляют соответственно 29 и $42 \%$.

Таким образом, для российских компаний управление на основе стоимости остается достаточно новой практикой. В то же время такой подход означает для инвесторов работающий механизм, который позволяет наращивать фундаментальную стоимость их бизнеса и ведет, таким образом, к увеличению их материальных выгод. Концепция EVA ${ }^{\circledR}$ является одним из наиболее популярных в реальном бизнесе методов экономической прибыли, на котором основано управление стоимостью компании. С одной стороны, этот показатель является простым для расчета, с другой - позволяет не только проводить оценку фундаментальной стоимости, но и служит показателем ее изменения и индикатором эффективности деятельности компании в каждый момент времени. В то же время создание в компании системы управления стоимостью и выбор конкретной модели экономической прибыли должны основываться на понимании действия и отраслевых особенностей бизнеса, и на внутренних характеристиках компании - элементов, которые оказывают ключевое влияние на стратегическую эффективность.

\section{Список литературы}

1. Ивашковская И.В. Влияние корпоративного управления на стратегическую эффективность российских компаний //Финансы и кредит. 2009. № 48.

2. Ивашковская И.В. Моделирование стоимости компании. Стратегическая ответственность советов директоров. М.: ИНФРА-М, 2010.

3. Ивашковская И.В., Животова Е.Л. Индекс устойчивости роста: эмпирический анализ российских компаний // Вестник Санкт-Петербургского университета. Серия менеджмент. 2009. № 3. 